\title{
ROOT KINEMATICS IN RELATION TO TEMPERATURE AND GENOME SIZE IN WILD AND DOMESTICATED ZEA.
}

\author{
A Thesis \\ Presented to \\ The Faculty of California Polytechnic State University, \\ San Luis Obispo \\ In Partial Fulfillment \\ of the Requirements for the Degree \\ Master of Science in Biological Sciences
}

By

Avery Bart Cromwell

June, 2013 
(C) 2013

Avery Bart Cromwell

\section{ALL RIGHTS RESERVED}

Page ii 
COMMITTEE MEMBERSHIP

TITLE:

AUTHOR:

DATE SUBMITTED:

COMMITTEE CHAIR:

COMMITTEE MEMBER:

COMMITTEE MEMBER:
Root kinematics in relation to temperature and genome size in wild and domesticated Zea.

Avery Bart Cromwell

June, 2013

Charles Knight, PhD

Associate Professor of Biological Sciences

Dr. Ed Himelblau, PhD

Associate Professor of Biological Sciences

Dr. Scott Steinmaus, PhD

Professor of Biological Sciences 


\begin{abstract}
Root kinematics in relation to temperature and genome size in wild and domesticated Zea.
\end{abstract}

\begin{abstract}
Avery Bart Cromwell
We studied root kinematics in relation to temperature and genome size variation in teosinte (Zea mays subspecies parviglumis) and corn (Zea mays subspecies mays). Corn had significantly faster radicle growth than teosinte when grown at a constant temperature. Both species exhibited variation in seed size and for each species larger seeds had faster root growth. Genome size was not significantly correlated with faster radicle growth rates across multiple land races of corn. To examine temperature dependent growth in corn and teosinte, a germinated seedling was grown at multiple temperatures. Growth rates at these temperatures were used to fit a temperature response model for each species. Parameters of this model (maximum growth temperature and optimum growth temperature) were not significantly different between the species.
\end{abstract}

Keywords: genome size, response curve, kinematics, 


\section{ACKNOWLEDGMENTS}

This paper was only accomplished through the generous time contributions of committee members and through the invaluable collaborative efforts of Concepción M. Díez. 


\section{TABLE OF CONTENTS}

Page

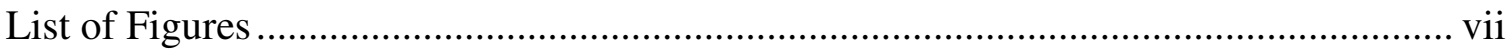

\section{Chapter}

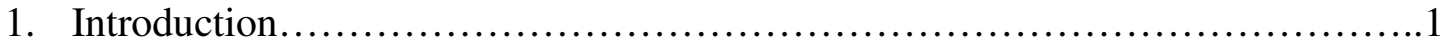

2. Methods and Materials.....................................................

3. Results ............................................................

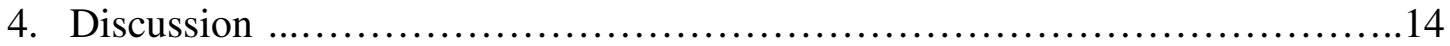

References.................................................................... 17 


\section{LIST OF FIGURES}

Figure

Page

1. Average growth rate at $23{ }^{\circ} \mathrm{C}$ for teosinte (white circle) and corn (black circle). Corn had a significantly faster growth rate. Error bars represent the standard error of the mean.

2. Incremental growth of root at $23{ }^{\circ} \mathrm{C}$ for teosinte (white circle) and corn (black circle) measured over 5 hours at 5 minute intervals. Constant rate of growth was observed during the trial period. There was a significant statistical difference in growth rates (Fig. 1)

3. Relationship between seed mass and maximum growth rate in teosinte (white circles) and corn (black circles). There was a significant positive correlation between seed mass and maximum growth rate for each species. The linear regression is modeled for each with the associated black lines and associated p-value and slope.

4. (a) Average weight of pre-imbibation teosinte (white circle) and corn (black circle) seeds. Corn had significantly greater mass than teosinte seeds. Error bars represent the standard error of the mean. (b) Images of a corn and teosinte seed with a $1 \mathrm{~mm}$ white bar for reference.

5. Temperature response parameters $\left(\mathrm{T}_{\max }\right.$ and $\left.\mathrm{T}_{\mathrm{opt}}\right)$ for teosinte (white circles) and corn (black circles). The dashed line represents independently derived published temperature parameter estimates for corn (Yan and Hunt, 1999). There was no significant difference between the temperature parameters for teosinte and corn . Error bars represent the standard error of the mean; nsd: no significant difference.

6. (a) Modeled temperature response curve for corn from previous studies using the temperature parameters $\mathrm{T}_{\max }$, (diamond) $\mathrm{T}_{\mathrm{opt}}$, (triangle) and $\mathrm{T}_{\min }$, incorporated into the model given at left. Modeled temperature response curve derived from multiple studies and multiple tissues in corn. (b) Average temperature response curve for corn (black line) predicted from multiple trials of corn seeds (grey lines). Independent seed trial analysis concluded temperature response curve for each seed dependent on measured relative growth rates in multiple temperatures (grey circles). Measured relative growth rates were used to fit the temperature response equation for each seed given a $T_{\min }$ of $9^{\mathrm{O}} \mathrm{C}$. Average $\mathrm{T}_{\max },\left(\right.$ diamond) and $\mathrm{T}_{\mathrm{opt}}$, (triangle) are displayed with 
their associated standard error bars which represent the standard error of the mean. (c) Average temperature response curve for teosinte (black line) predicted from multiple trials of teosinte seeds (grey lines). Independent seed trial analysis concluded temperature response curve for each seed dependent on measured relative growth rates in multiple temperatures (open grey circles). Measured relative growth rates were used to fit the temperature response equation for each seed given a $\mathrm{T}_{\min }$ of $9^{\circ} \mathrm{C}$. Average $\mathrm{T}_{\max },\left(\right.$ diamond) and $\mathrm{T}_{\mathrm{opt}}$, (triangle) are displayed with their associated standard error bars which represent the standard error of the mean. 


\section{CHAPTER 1}

Introduction

Plant growth is highly influenced by temperature. Variation in growth under different climate conditions can have a significant economic impact. Heat stress from high temperatures in 2011 alone cost the U.S. billions in lost crops (Chen et al., 2012). Heat waves are a product of extreme weather conditions and are likely to increase in frequency with climate change (Southworth et al., 2000). Increasing crop loss due to thermal stress makes research in and understanding of the temperature response of corn important, especially with the potentially severe effects of future climate change.

Previous studies have used a temperature response equation that incorporated three temperature parameters to model the relative growth dependant on temperature in Zea (Yan and Hunt, 1999; Van Esbroeck et al., 2008). The equation $r e l=\left(\frac{T_{\max }-T}{T_{\max }-T_{o p t}}\right)\left(\frac{T-T_{\min }}{T_{o p t}-T_{\min }}\right)^{\frac{\left(T_{\max }-T_{o p t}\right)}{\left(T_{o p t}-T_{\min }\right)}}$ describes the relative growth (rel) of any plant tissue at any temperature $(\mathrm{T})$ as a product of three temperature parameters: the maximum temperature $\left(T_{\max }\right)$ for growth, minimum temperature $\left(T_{\min }\right)$ for growth, and the optimum temperature $\left(\mathrm{T}_{\mathrm{opt}}\right)$ where growth is the fastest. It has previously been established that at $9^{\circ} \mathrm{C}$ no appreciable growth occurs in the radicle (Blacklow, 1972). We will use this as the temperature minimum $\left(\mathrm{T}_{\min }\right)$ for all of our trials. Therefore, our temperature response experiments will be used only to infer the temperature optimum and maximum temperature $\left(\mathrm{T}_{\mathrm{opt}}\right.$, and $\left.\mathrm{T}_{\max }\right)$. 
Modelling growth rate in plants dependant on temperature has become well established practice, but the effect of varying genome size on growth rate is not as well understood. There is significant variation in genome size across plant species. The magnitude of this variation can be as large as $>2000$ fold for 1C DNA content (the haploid complement of a plant genome (Bennett \& Smith, 1976). Cultivated corn land races in Mexico contain significant variation in genome size (Díez et al., 2013) but how this affects growth and other aspects of its biology is unknown.

While gene duplications play a role in generating variation in genome size, by far the largest contributor to genome expansion results from the amplification of transposable elements (Bennetzen, 2000). Whole genome duplication (polyploidy) with eventual rediploidization also plays a significant role (Grover and Wendel, 2010), though polyploidy itself does not increase the haploid genome size (Greilhuber, 2005). The effect of DNA accumulation on plant evolution, ecology, and physiology is not well understood and represents a major unanswered question in plant biology (Knight et al., 2005).

The role this genetic variation has in evolution of plant taxa is currently an area of active research. The strongest link between genome size and phenotype has been observed at the cellular level (Beaulieu et al., 2008). Measured across 101 species of angiosperms, guard cell length, and epidermal cell area, were both significantly correlated with genome size. Even within individual genera like Allium, a pattern of species with a larger genome also having larger guard cells has been observed (Lomax at al., in press). 
Genome size has also been shown to impact aspects of physiology. Gruner et al. (2010) investigated root apical meristem growth in a number of species with varying genome size. They found that larger genome species had slower root apical meristem growth. Root apical meristem growth is a function of cell division rate. Plants with larger genomes had an associated slower cell division rate (Francis et al., 2008). Roots must constantly grow for a plant to continue to access new nutrient stores as it depletes local resources (Fransen et al., 1998). A reduced rate of root growth would impact a plants ability to acquire nutrients from the environment.

It is the goal of this study to further explore the effect of genome size and temperature on root growth kinematics. If larger genomes increase the time necessary for the cell cycle we expect that larger genome species to have a reduced root growth rate. A secondary goal was to chart the temperature response curve of corn and teosinte for direct comparison. As the distribution of corn crops and teosinte overlap in regions where teosinte is native (Diez et al. 2013) and therefore share a similar climate, we expect that both species to have a similar temperature response curve. 


\section{CHAPTER 2}

\section{Methods and Materials}

Teosinte and corn seeds used for establishing the temperature response curve were acquired through the USDA (Ames 21803 lot 92ncao01 and Ames 27261 lot 07ncai02). We also obtained seeds from various land races collected in Mexico by Concepcion Munez (Diez et al., 2013) along two altitudinal gradients in the states of Guerrero, Molrelos and Estado de Mexico.

Seeds were germinated in the dark at $25.5^{\circ} \mathrm{C}^{+} /-1^{\circ}$. Plants were kept at an incline of $30^{\circ}$ in enclosed dishes on filter paper with $1 \mathrm{ml}$ of water added approximately every 24 hours. The incline encouraged linear growth of the radicle easing future analysis. Germination usually occurred within 48-72 hours. Kinematic measurements were taken when roots were between $3-10 \mathrm{~cm}$. At this size growth was entirely dependent on energy reserves (i.e. catabolic growth) because the cotyledons had not emerged (Warrington and Kanemasu, 1983).

For measurments plants were placed in an enclosed plate at an angle of $70^{\circ}$. Two moistened filter sheets were placed under a piece of black construction paper. These were added to maintain adequate water availability and provide contrast image analysis. Trials began with a 30 minute equilibration period when seeds were kept in the trial plate at the first temperature regime. Temperature was controlled through a thermoelectric heater attached to the base of the enclosed plate. Temperatures were measured beneath the seed while contacting the construction paper using a thermocouple. 
The temperature of each regime used in the analysis was the average temperature for the 30 minute temperature regime. Temperature was changed using a thermoelectric controller. We ran seeds at 4 or 5 different temperature regimes between $75^{\circ}$ and $115^{\circ}$. Trials began at the lowest temperature and ratcheted up every thirty minutes. Temperatures were kept constant for the 30 minute temperature regime after the initial period of increase, which lasted less than 3 minutes.

Trials lasted approximately 3 hours with the equilibration period. Photos were taken every 5 minutes during the trial. During data acquisition a constant low light source of 3 watts held at an approximate distance of $16 \mathrm{~cm}$.

Average growth for a given temperature was inferred from the 6 photos taken at each temperature. We used mTrackj (a plug-in for Image $\mathbf{J}$ ) to measure the radicle growth. For each temperature regime there were 6 photos which provided 6 measurements for distance grown. These 6 measurements were averaged for the growth rate at that temperature. Each seed was considered a separate replicate and total there were 10 replicates for teosinte and 13 for corn. Data was omitted if there was any movement in the radicle tip that could not be attributed to linear growth of the root (twisting or falling). Any time the radicle receded or shrank, it was included as 0 growth for that time period.

Relative growth rates were calculated by dividing the average growth rate of the radicle at each temperature by its maximum average rate of growth for the trial. Measurements for relative growth rate varied between 0 and 1 . Relative growth rates were used to infer the two temperature parameters for the temperature response model. 
The model function we used to approximate the temperature parameters for root growth contains multiple independent variables. Nonlinear regression was used to infer the two temperature parameters $\left(\mathrm{T}_{\mathrm{opt}}\right.$ and $\left.\mathrm{T}_{\max }\right)$ for each seed using Minitab. The temperature minimum used in all calculations was $9^{\circ} \mathrm{C}$ (Cross \& Zuber, 1972). Two sample T-tests were used to compare temperature parameters across species. 


\section{CHAPTER 3}

Results

Corn had a significantly faster root growth rate at $23^{\circ} \mathrm{C}$ (p-value $<0.05$, Figure 1.) with an average rate of $.025 \mathrm{~mm} /$ minute (sample size of 4 seeds). Held at a constant temperature, radicle growth was straight line linear for both teosinte and corn (Figure 2.). Teosinte had a slower average rate of growth $0.014 \mathrm{~mm} / \mathrm{minute}$ (sample size of 6 seeds). Seed mass was significantly positively correlated with the maximum rate of root growth within both corn and teosinte (p-value $<0.05$, Figure 3.). Corn also had a significantly larger mean seed mass ( $\mathrm{p}$-value $<0.05$, Figure 4.). There was no significant correlation between genome size and maximum rate of root growth in Mexican land races of corn (data not shown) using a sample size of 15 seeds containing 4 different genotypes. There was no significant difference between the corn and teosinte for temperature dependent growth kinematic parameters $\mathrm{T}_{\mathrm{opt}}$ and $\mathrm{T}_{\max }$ (p-value>.05, Figure 5.), and curves inferred from each trial vary around the average temperature response curve for corn and teosinte (Figure 6.). There was no significant correlation between genome size and root growth rate (data not shown). 


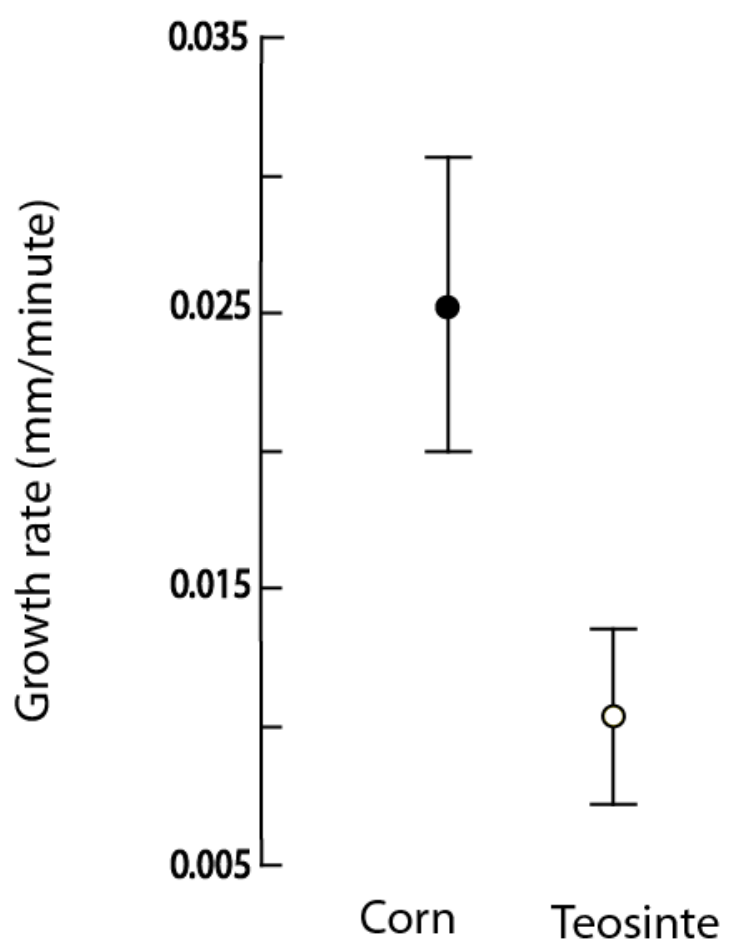

Figure 1. Average growth rate at $23{ }^{\circ} \mathrm{C}$ for teosinte (white circle) and corn (black circle). Corn had a significantly faster growth rate. Error bars represent the standard error of the mean. 


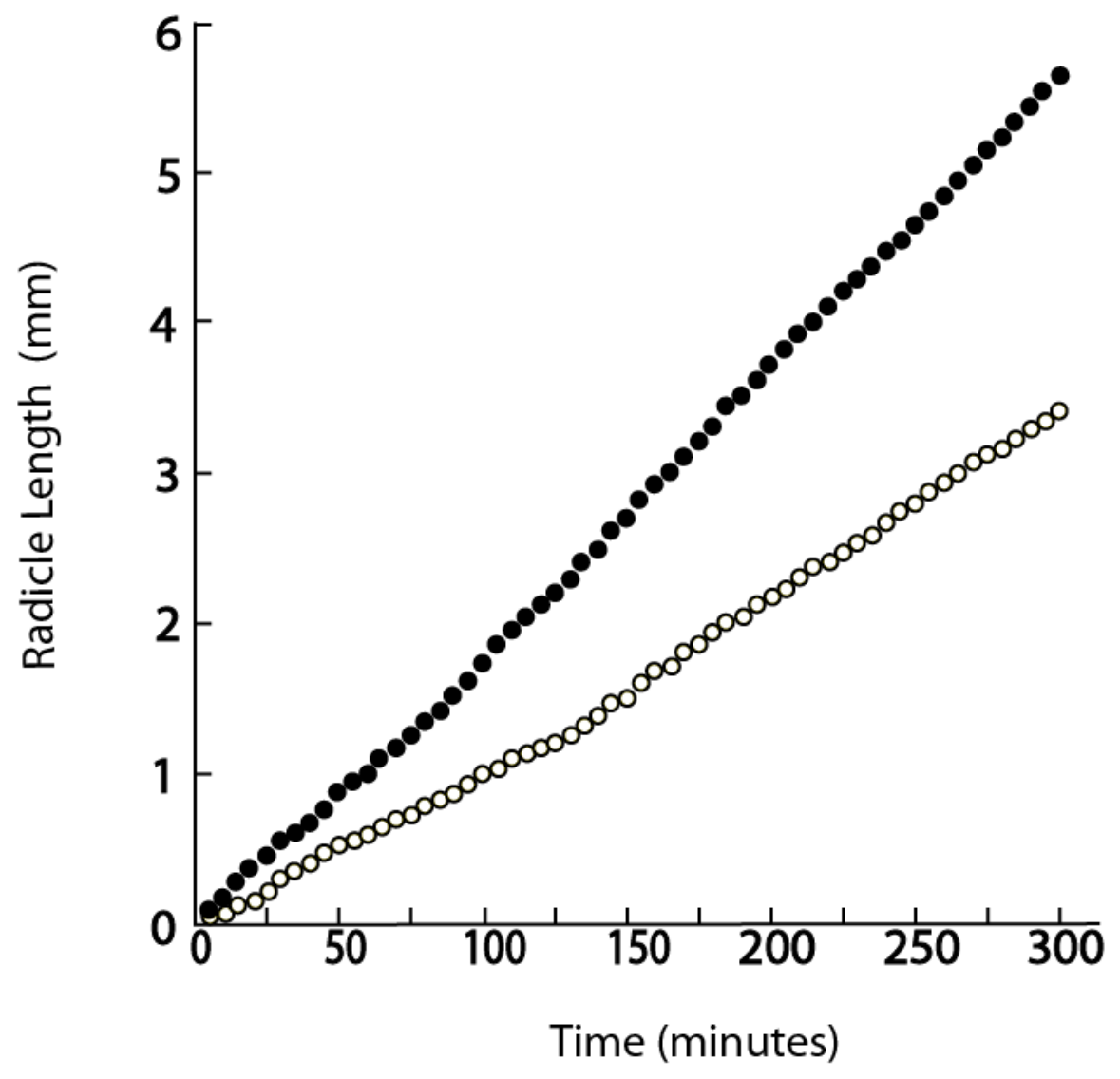

Figure 2. Incremental growth of root at $23{ }^{\circ} \mathrm{C}$ for teosinte (white circle) and corn (black circle) measured over 5 hours at 5 minute intervals. Constant rate of growth was observed during the trial period. There was a significant statistical difference in growth rates (Fig. 1) 


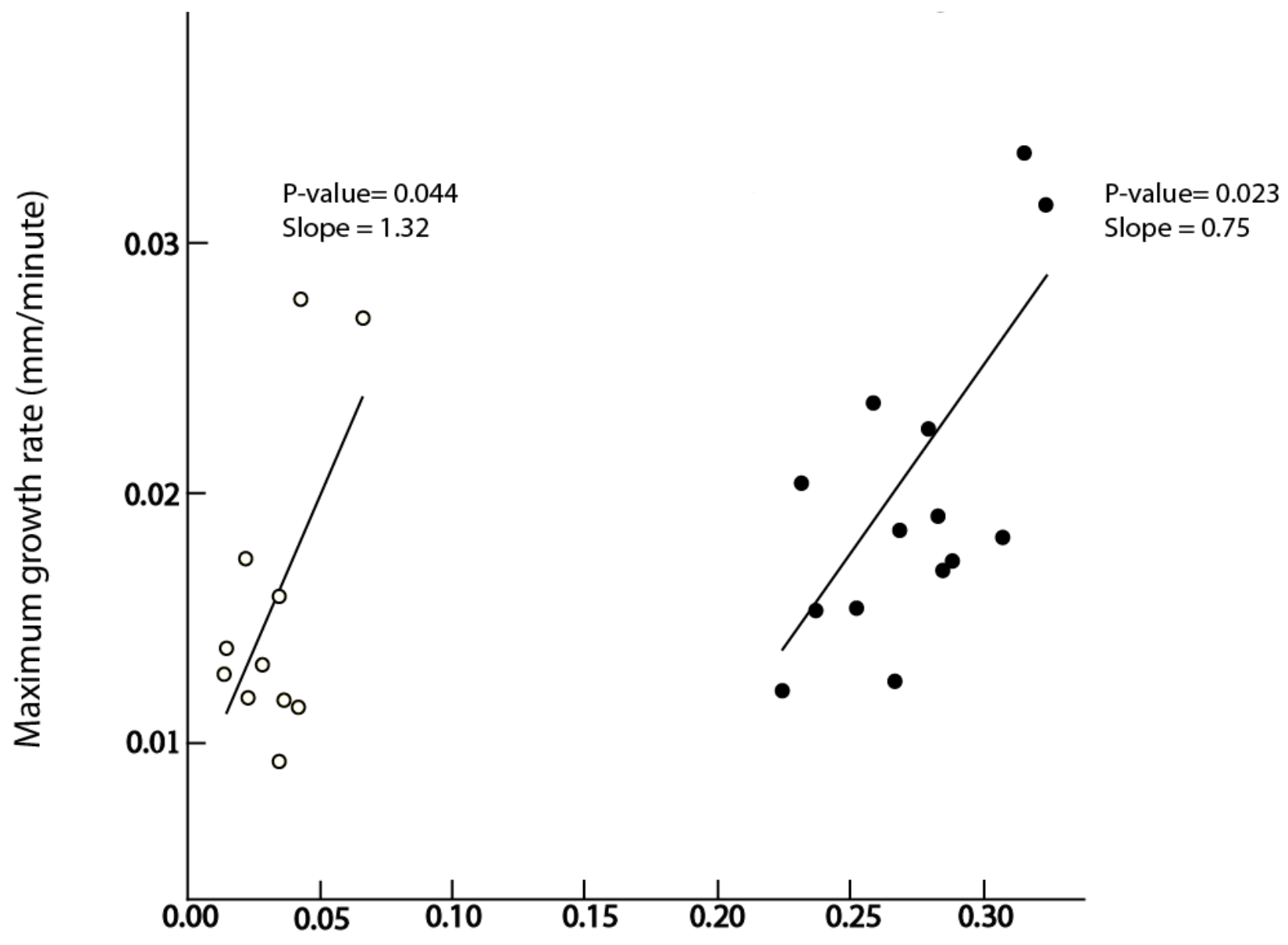

Weight (g)

Figure 3. Relationship between seed mass and maximum growth rate in teosinte (white circles) and corn (black circles). There was a significant positive correlation between seed mass and maximum growth rate for each species. The linear regression is modeled for each with the associated black lines and associated p-value and slope. 


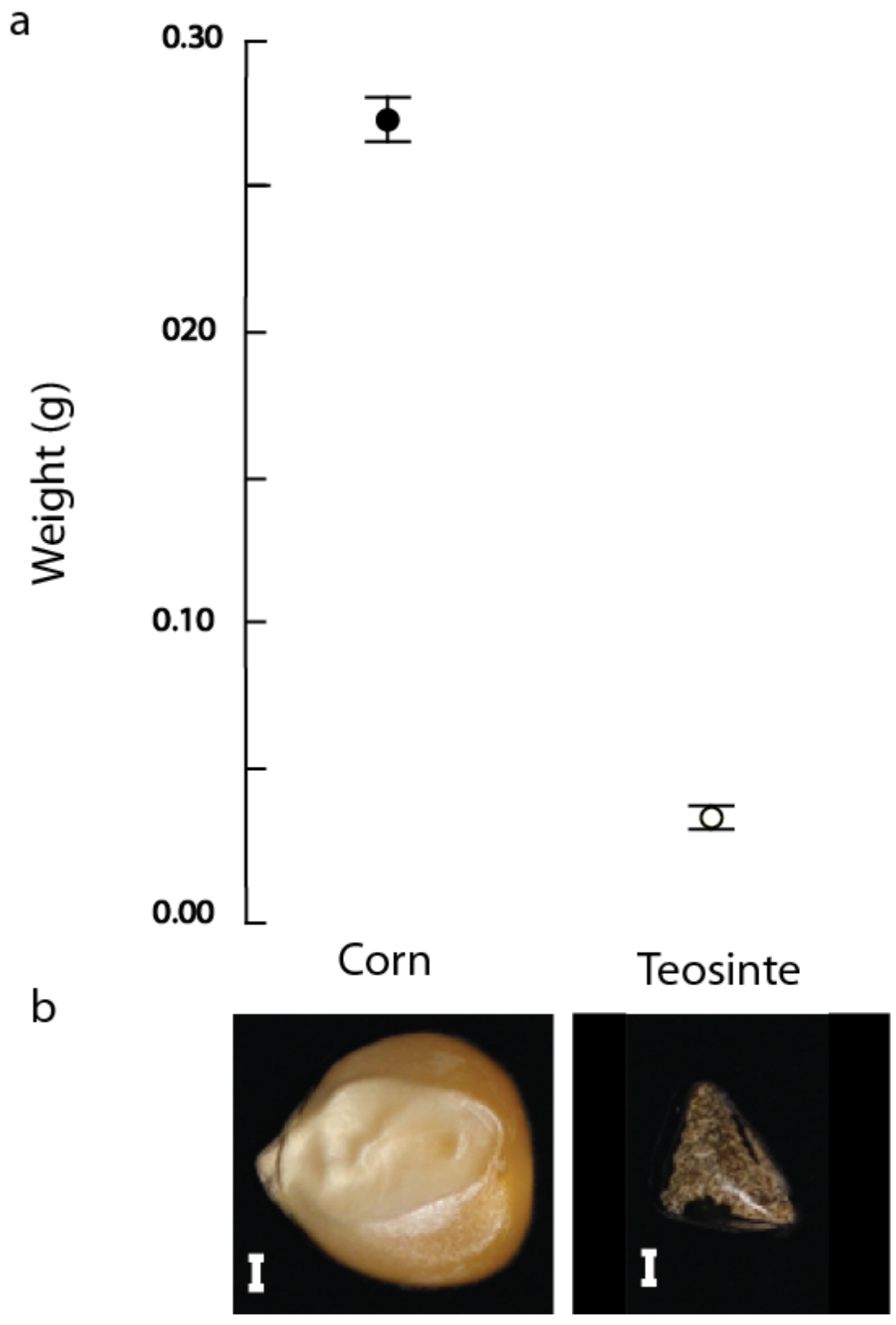

Figure 4.- (a) Average weight of pre-imbibation teosinte (white circle) and corn (black circle) seeds. Corn had significantly greater mass than teosinte seeds. Error bars represent the standard error of the mean. (b) Images of a corn and teosinte seed with a $1 \mathrm{~mm}$ white bar for reference. 


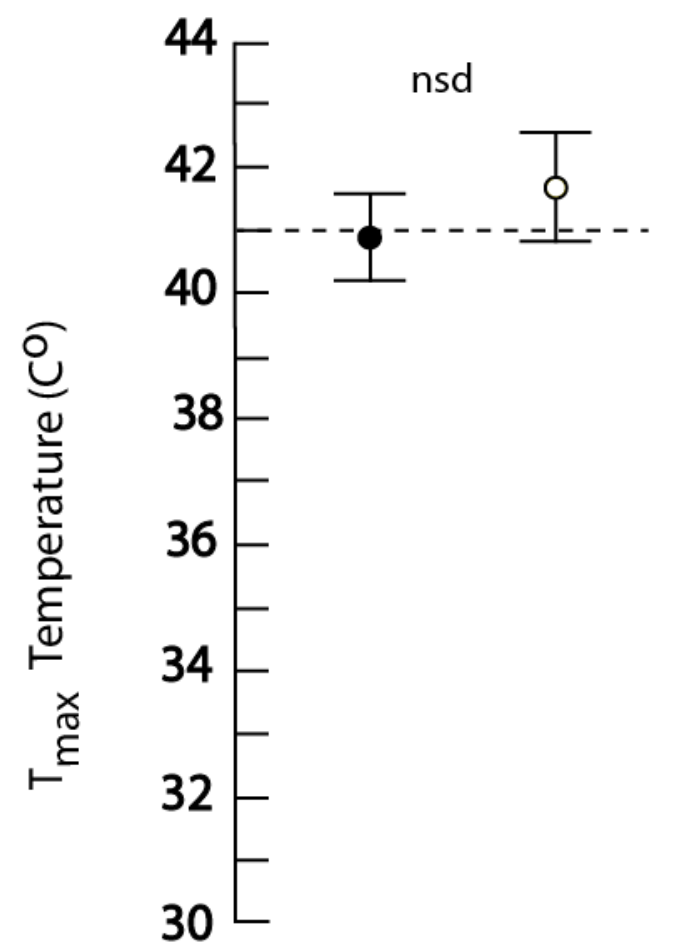

Corn Teosinte

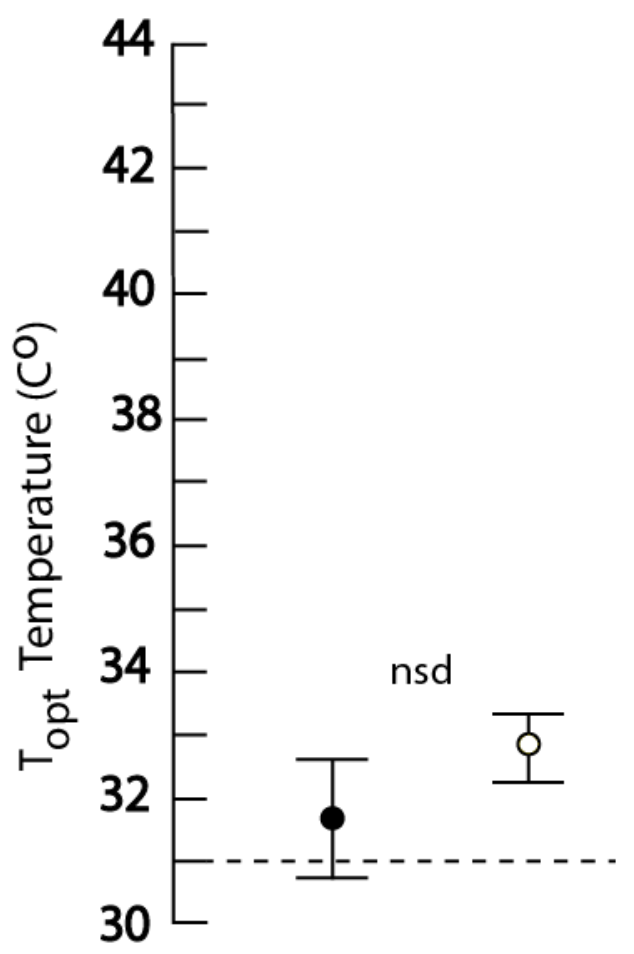

Corn Teosinte

Figure 5.- Temperature response parameters $\left(\mathrm{T}_{\max }\right.$ and $\left.\mathrm{T}_{\mathrm{opt}}\right)$ for teosinte (white circles) and corn (black circles). The dashed line represents independently derived published temperature parameter estimates for corn (Yan and Hunt, 1999). There was no significant difference between the temperature parameters for teosinte and corn . Error bars represent the standard error of the mean; nsd: no significant difference. 
a
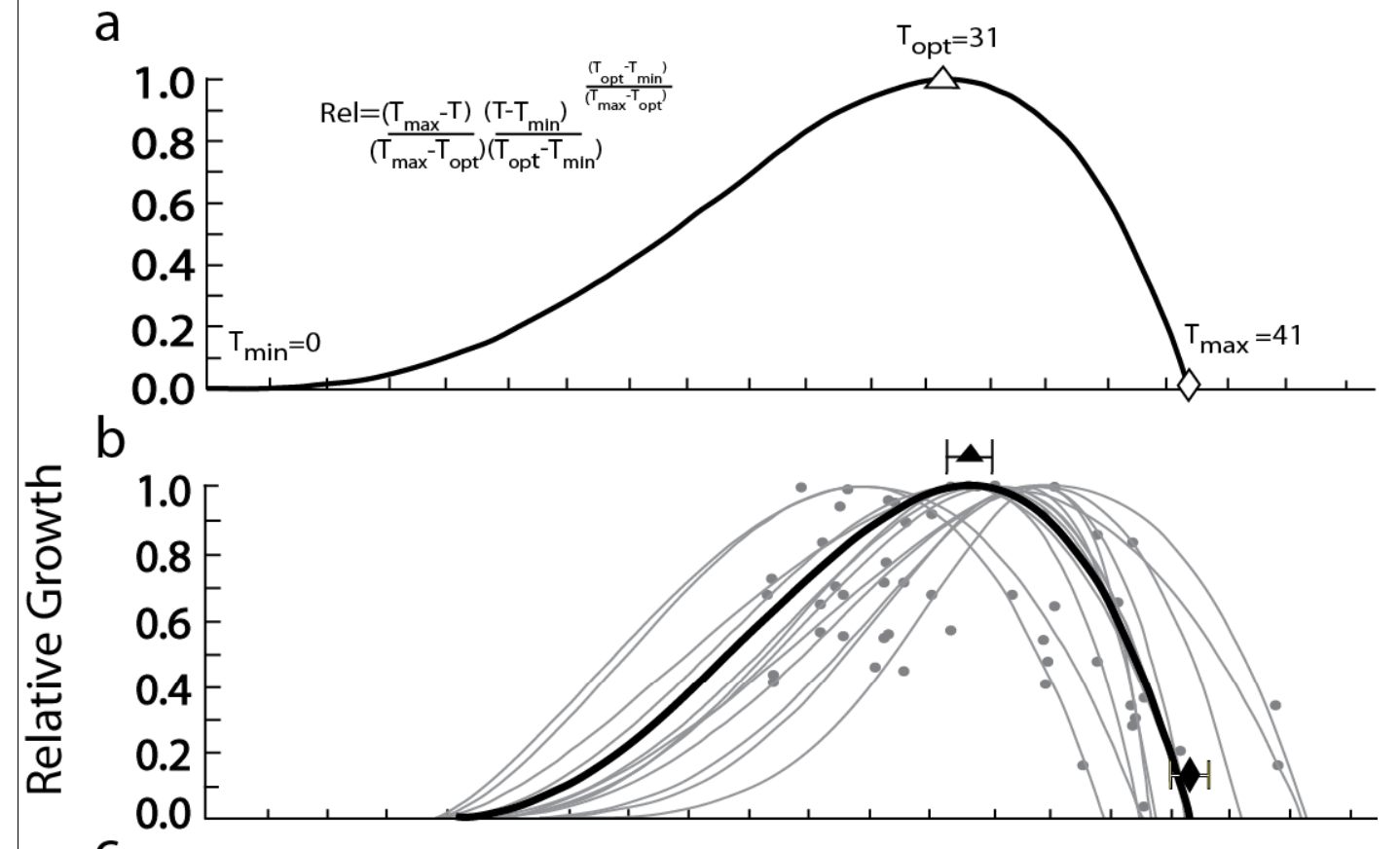

C

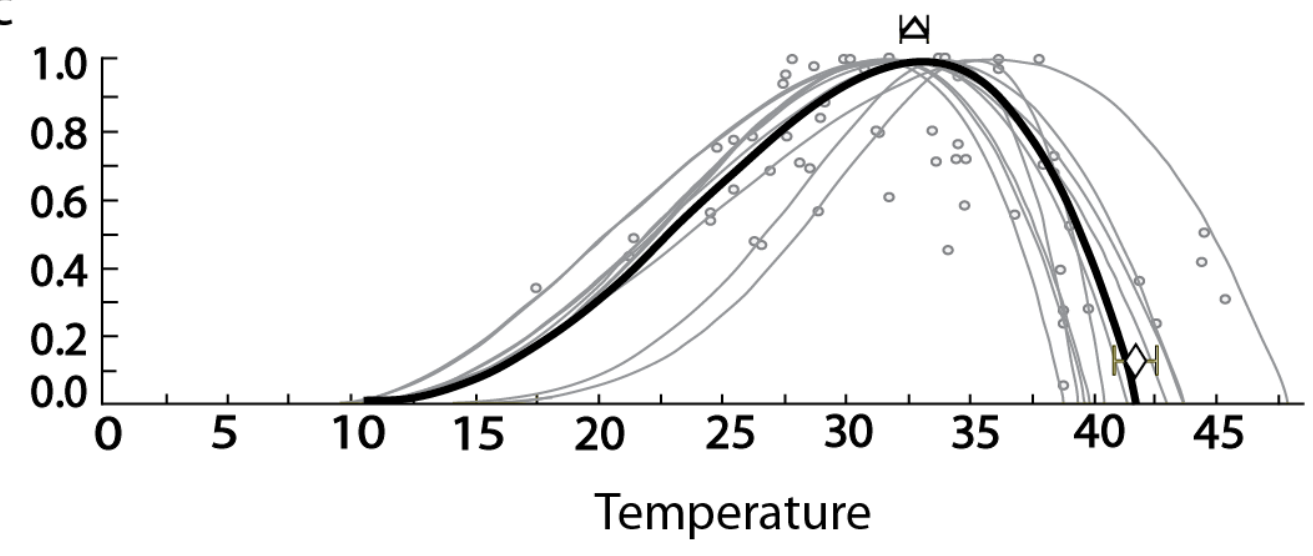

Figure 6.- (a) Modeled temperature response curve for corn from previous studies using the temperature parameters $\mathrm{T}_{\max }$, (diamond) $\mathrm{T}_{\mathrm{opt}}$, (triangle) and $\mathrm{T}_{\min }$, incorporated into the model given at left. Modeled temperature response curve derived from multiple studies and multiple tissues in corn. (b) Average temperature response curve for corn (black line) predicted from multiple trials of corn seeds (grey lines). Independent seed trial analysis concluded temperature response curve for each seed dependent on measured relative growth rates in multiple temperatures (grey circles). Measured relative growth rates were used to fit the temperature response equation for each seed given a $\mathrm{T}_{\min }$ of $9^{\circ} \mathrm{C}$. Average $\mathrm{T}_{\max }$, (diamond) and $\mathrm{T}_{\mathrm{opt}}$, (triangle) are displayed with their associated standard error bars which represent the standard error of the mean. (c) Average temperature response curve for teosinte (black line) predicted from multiple trials of teosinte seeds (grey lines). Independent seed trial analysis concluded temperature response curve for each seed dependent on measured relative growth rates in multiple temperatures (open grey circles). Measured relative growth rates were used to fit the temperature response equation for each seed given a $\mathrm{T}_{\min }$ of $9^{\circ} \mathrm{C}$. Average $\mathrm{T}_{\max }$, (diamond) and $\mathrm{T}_{\mathrm{opt}}$, (triangle) are displayed with their associated standard error bars which represent the standard error of the mean. 


\section{CHAPTER 4}

\section{Discussion}

Absolute growth rate was significantly different between corn and teosinte but the temperature kinetics of growth were not. The parameters $T_{\max }$ and $\mathrm{T}_{\mathrm{opt}}$ were not significantly different between species. The relative growth rate modeled by the temperature response curve shows a similar response to temperature in corn and teosinte. The temperatures for $\mathrm{T}_{\max }$ and $\mathrm{T}_{\mathrm{opt}}$ for corn root growth rate agree with previously published temperature parameters for leaf appearance, the tassel initiation, leaf elongation and dry matter production (Yan \& Hunt, 1999). At each temperature the relative growth for corn was approximately equal to teosinte. The upper threshold, where growth is prevented by thermal stress, is nearly identical in the two species. Thermal tolerance during domestication has remained remarkably consistent in the Zea genus. Though the temperature kinetics of relative growth remained consistent the absolute growth rate at $23^{\circ} \mathrm{C}$ is greater in corn compared to its wild relative.

Constant tissue growth is possible among grasses without environmental limitations. The linear relationship between time and radicle length at a fixed temperature found in this study is similar to other findings which have shown linear leaf-tip and lingule development for multiple genotypes and temperatures (Esbroeck et al., 2008). These studies used constant temperature and copious water and nutrient availability. For grasses adapted for short generation times and rapid growth this balance for grasses is 
theorized to maximize relative growth rate (Hilbert, 1990). However natural

environments are not this static so growth is constantly varying with temperature or inhibited by other limiting factors (nutrients, energy, or water).

Root growth prior to development of functional photosynthetic tissue is dependent on energy reserves stored in the endosperm (catabolic growth); (Cooper \& MacDonald, 1970). Larger seeds have larger reserves of available energy. Without any diminishing rates of growth over the 5 hour time period it is likely that seedlings do not exhaust their energy reserve until much later. Previous studies have shown that seeds grown in light or dark had similar growth rates until 10 days after germination (Cooper \& MacDonald, 1970). Energy from photosynthesis does not provide a significant contribution to plant growth until well beyond our experimental window.

The small variability of seed sizes in corn and teosinte are consistent with stabilizing selection. Faster root growth rates would provide a relative advantage for nutrient acquisition in plants with larger seeds (Ingestad \& Kähr, 1985). But genetic constraints have evolved to control seed size to optimize parental fitness (Mihaljevic et $a l ., 2004)$. This has led to high variability in seed number with constrained variation in seed size in response to environmental changes for grains (Puckridge \& Donald, 1967). Inconsistent with this trend, the Zea genus has a relatively large plasticity in seed size (although still smaller than variation in seed number) but this is predominately due to selective breeding in corn for fewer viable inflorescences. Teosinte has a considerably less plasticity in seed size and both species exhibit a far greater ability to produce more seeds than produce larger seeds (Hanway, 1969; Sadras, 2007). In addition due to 
minimal environmental variation plants grown at the USDA our seeds exhibit little very variation for seed mass.

Although our findings did not find a relationship between genome size and root growth rate, previous studies have shown a negative correlation between the two (Gruner et al., 2010). This was observed across species with large variation in genome size.

Genome size did differ significantly in the land races investigated (Díez et al., 2013). Other research has shown genome size also did not significantly affect leaf appearance rates in Zea (Esbroeck et al., 2008). Future research is necessary to distinguish whether these studies are unusual for the Zea genus. Domestication may have muted the effect of genome size in tissue growth rate. Further work will need a comparison study with multiple genotypes of teosinte and other domesticated species. 


\section{References}

Beaulieu JM, Leitch IJ, Patel S, Pendharkar A, Knight CA. 2008. Genome size is a strong predictor of cell size and stomatal density in angiosperms. New Phytologist 179: 975-986.

Bennett MD, Smith JB. 1976. Nuclear DNA Amounts in Angiosperms. Philosophical Transactions of the Royal Society of London. B, Biological Sciences 274: 227274.

Bennetzen JL. 2000. Comparative Sequence Analysis of Plant Nuclear Genomes:

Microcolinearity and Its Many Exceptions. The Plant Cell Online 12: 1021-1029.

Blacklow WM. 1972. Influence of Temperature on Germination and Elongation of the Radicle and Shoot of Corn (Zea mays L.). Crop Science 12: 647-650.

Chen J, Xu W, Velten J, Xin Z, Stout J. 2012. Characterization of maize inbred lines for drought and heat tolerance. Journal of Soil and Water Conservation 67: 354-364.

Cooper CS, MacDonald PW. 1970. Energetics of Early Seedling Growth in Corn (Zea mays L.). Crop Science 10: 136-139.

Cross HZ, Zuber MS. 1972. Prediction of Flowering Dates in Maize Based on Different Methods of Estimating Thermal Units. Agronomy Journal 64: 351-355.

Díez CM, Gaut BS, Meca E, Scheinvar E, Montes-Hernandez S, Eguiarte LE, Tenaillon MI. 2013. Genome size variation in wild and cultivated maize along altitudinal gradients. The New phytologist 199: 264-276. 
Francis D, Davies MS, Barlow PW. 2008. A Strong Nucleotypic Effect on the Cell Cycle Regardless of Ploidy Level. Annals of Botany 101: 747-757.

Fransen B, Kroon H de, Berendse F. 1998. Root morphological plasticity and nutrient acquisition of perennial grass species from habitats of different nutrient availability. Oecologia 115: 351-358.

Greilhuber J, Doležel J, Lysák MA, Bennett MD. 2005. The Origin, Evolution and Proposed Stabilization of the Terms 'Genome Size' and 'C-Value' to Describe Nuclear DNA Contents. Annals of Botany 95: 255-260.

Grover CE, Wendel JF. 2010. Recent Insights into Mechanisms of Genome Size Change in Plants. Journal of Botany 2010.

Gruner A, Hoverter N, Smith T, Knight CA. 2010. Genome size is a strong predictor of root meristem growth rate. Journal of Botany 2010.

Hanway JJ. 1969. Defoliation Effects on Different Corn (Zea mays, L.) Hybrids as Influenced by Plant Population and Stage of Development. Agronomy journal 61: $534-538$.

Hilbert DW. 1990. Optimization of Plant Root: Shoot Ratios and Internal Nitrogen Concentration. Annals of Botany 66: 91-99.

Ingestad T, Kähr M. 1985. Nutrition and growth of coniferous seedlings at varied relative nitrogen addition rate. Physiologia Plantarum 65: 109-116.

Knight CA, Molinari NA, Petrov DA. 2005. The Large Genome Constraint Hypothesis: Evolution, Ecology and Phenotype. Annals of Botany 95: 177-190. 
Mihaljevic R, Utz HF, Melchinger AE. 2004. Congruency of quantitative trait loci detected for agronomic traits in testcrosses of five populations of European maize. Crop science 44: 114-124.

Puckridge D, Donald C. 1967. Competition among wheat plants sown at a wide range of densities. Australian Journal of Agricultural Research 18: 193-211.

Sadras VO. 2007. Evolutionary aspects of the trade-off between seed size and number in crops. Field Crops Research 100: 125-138.

Southworth J, Randolph JC, Habeck M, Doering OC, Pfeifer RA, Rao DG, Johnston JJ. 2000. Consequences of future climate change and changing climate variability on maize yields in the midwestern United States. Agriculture, Ecosystems \& Environment 82: 139-158.

Van Esbroeck GA, Ruiz Corral JA, Sanchez Gonzalez JJ, Holland JB. 2008. A comparison of leaf appearance rates among teosinte, maize landraces and modern maize. Maydica 53: 117.

Warrington IJ, Kanemasu ET. 1983. Corn Growth Response to Temperature and Photoperiod I. Seedling Emergence, Tassel Initiation, and Anthesis. Agronomy Journal 75: 749-754.

Yan W, Hunt LA. 1999. An Equation for Modelling the Temperature Response of Plants using only the Cardinal Temperatures. Annals of Botany 84: 607-614. 